\title{
Urgent message from the Editor-in-Chief regarding duplicate submission
}

\author{
Nobuhisa Hagiwara
}

Published online: 11 December 2010

(c) Springer 2010

November 5, 2010

The Editors of Heart and Vessels have confirmed that a manuscript that was submitted to our journal in December 2009 from a university in China was also submitted to another journal at the same time.

It is our policy that manuscripts submitted to this journal must not be under simultaneous consideration by any other journals. It is the authors' responsibility to make the assertion that a manuscript has not been published before, and is not under consideration for or under publication elsewhere.
Duplicate submission is a crime violating ethical guidelines regarding the scientists' agreement.

As the Editor-in-Chief of Heart and Vessels, I must protest strongly against duplicate submission and sincerely hope that it will never happen again.

Nobuhisa Hagiwara

Editor-in-Chief

Heart and Vessels

N. Hagiwara ( $\square)$

Tokyo Women's Medical University,

8-1 Kawada-cho, Shinjuku-ku,

Tokyo 162-8666, Japan

e-mail: mhagi@hij.twmu.ac.jp 